Herta Nagl-Docekal*

\title{
Nach einer erneuten Lektüre: Max Horkheimer, Die Sehnsucht nach dem ganz Anderen
}

\author{
https://doi.org/10.1515/dzph-2020-0046
}

\begin{abstract}
What we call meaning is bound to vanish": Under this heading, an interview with Max Horkheimer was published in Der Spiegel (Jan 5, 1970). Revisiting this interview, the article focuses on Horkheimer's thesis that human beings share the "longing that the injustice which characterizes the world must not be the final word". It examines the extent to which Horkheimer's notion of the "desire for the totally other" may be inspired by Kant's claim that religion is grounded in the "need of practical reason". A further topic of discussion is Horkheimer's critical assessment concerning current tendencies toward a "total administration of the world" that may ultimately "reduce thinking to the level of industrial processes". Relating this critique to Kant's reflections on the "unbelief of reason (Vernunftunglaube)", which is based on "the maxim of reason's independence of its own need", the article raises the question of Horkheimer's significance today: What relevance does Horkheimer's method of casting doubt on any "politics that is not based on theology, metaphysics and, of course, morality" have for today's discourse on such matters? In this context a brief glance is cast at Jürgen Habermas's post-metaphysical reading of Horkheimer's "negative theology". 1
\end{abstract}

Keywords: injustice, morality, negative theology, postulates of practical reason, total administration of the world, meaning of life

Unter dem Titel „Was wir ,Sinn“ nennen, wird verschwinden“ veröffentlichte Der Spiegel am 5. Januar 1970 ein Gespräch mit Max Horkheimer, im Vorfeld seines 75. Geburtstags; Interviewpartner waren die beiden Redakteure Georg Wolff

1 Die Forschung zu diesem Beitrag wurde durch das Russian Academic Excellence Project at the Immanuel Kant Baltic Federal University unterstützt.

*Kontakt: Herta Nagl-Docekal, Universität Wien, Institut für Philosophie, Universitätsstraße 7, 1010 Wien, Österreich; Immanuel Kant Baltic Federal University, Aleksandra Nevskogo Street 14, 236016 Kaliningrad, Russische Föderation; herta.nagl@univie.ac.at

๖ Open Access. (C) 2020 Nagl-Docekal, publiziert von De Gruyter. (c) BY Dieses Werk ist lizenziert unter der Creative Commons Attribution 4.0 Lizenz. 
und Helmut Gumnior. ${ }^{2}$ Im Zentrum dieses Gesprächs steht der Gedanke Horkheimers, „man solle Theologie erneuern“3, der für eine auf „Sehnsucht“, nicht Dogmatik, begründete Theologie plädiert - auf „Sehnsucht danach, dass es bei dem Unrecht, durch das die Welt gekennzeichnet ist, nicht bleiben soll. Dass das Unrecht nicht das letzte Wort sein möge. Diese Sehnsucht gehört zum wirklich denkenden Menschen“4. Präzisierend fährt Horkheimer fort: „Wir können nicht behaupten, es gäbe einen guten und allmächtigen Gott“; „Adorno und ich - wer von uns beiden es zuerst formuliert hat, weiß ich heute nicht mehr [haben] nicht mehr von Gott, sondern von der ,Sehnsucht nach dem Anderen“ gesprochen.“5 Die Anmerkung seiner Gesprächspartner, „diese Behutsamkeit im Umgang mit Gottes Namen ist - wie häufig festgestellt - jüdisches Erbe“, greift Horkheimer mit einem „Ja“ auf, wobei er ergänzt, „dass diese Behutsamkeit in unsere Gesellschaftstheorie, die wir die Kritische nannten, eingegangen ist. ,Du sollst Dir kein Bild von Gott machen', heißt es in der Bibel. Du kannst nicht darstellen, was das absolute Gute ist. [...] So nennt auch die Kritische Theorie das Absolute vorsichtig ,das Andere، " ${ }^{6}$ Doch bleibe Theologie, auch in dieser auf Sehnsucht begründeten Form, relevant für einen angemessenen Begriff von Praxis. Horkheimer insistiert darauf, „dass Politik, welche nicht Theologie oder Metaphysik, damit natürlich auch Moral, in sich bewahrt, letzten Endes Geschäft bleibe“, und setzt erläuternd fort: „Alles, was mit Moral zusammenhängt, geht logisch letzten Endes auf Theologie, jedenfalls nicht auf säkulare Gründe zurück."7

Als dieses (hier zunächst nur in Umrissen skizzierte) Interview vor fünfzig Jahren publiziert wurde, rief es einen Sturm der Entrüstung hervor. „Man kann sich heute kaum vorstellen, welch erhitzte Debatte auf das Interview folgte. Von einer ,Bekehrung، Horkheimers sprachen die einen, andere nannten es Verrat an der kritischen Philosophie der Frankfurter Schule. "8 Sowohl bei orthodoxen Marxisten als auch in Kreisen der Studentenbewegung, die „die Philosophie der Frankfurter Schule zu einem Leitbild“ erhoben hatte, riefen Horkheimers Thesen geradezu einen „Schock“ hervor ${ }^{9}$. Auch weit über diese Personenkreise hinaus erregte das Interview Aufsehen; Horkheimer wurde zu einem „Gegenstand der

2 Der Spiegel (1970), 79-84.

3 Ebd., 81.

4 Ebd.

5 Ebd.

6 Ebd.

7 Ebd., 80.

8 Dietrich (2009).

9 Ebd. Vgl. auch Gumnior (1970), 5. 
Massenmedien“10. Eine differenzierte Auseinandersetzung wurde dadurch in die Wege geleitet, dass Helmut Gumnior noch im gleichen Jahr eine ergänzte, leicht überarbeitete Fassung des Interviews, zusammen mit einem biographische und theoretische Hintergründe erhellenden Kommentar, publizierte ${ }^{11}$. Die hier folgenden Überlegungen werden vor allem auf diese Fassung Bezug nehmen. Den Fokus wird der Versuch bilden, den philosophischen Kern der Ausführungen Horkheimers deutlich zu machen und darauf hin zu befragen, ob bzw. wie weit er heute, nach einem halben Jahrhundert, Aktualität beanspruchen könnte.

\section{„Wenn schon, dann müssen Sie von einer Rückkehr sprechen!“}

Gumnior berichtet, er habe Horkheimer die Frage gestellt, „wie es zu seiner Wandlung vom revolutionären Optimisten zum Pessimisten gekommen sei. Erstaunt sah er mich damals an und sagte: ,Wenn schon, dann müssen Sie von einer Rückkehr sprechen!““ (5). Enthält diese Antwort den Schlüssel zum Verständnis zentraler philosophischer Intentionen des Spätwerks Horkheimers? Auf der Hand liegt zunächst, dass sie auf unterschiedliche Zusammenhänge bezogen werden kann: Erstens darauf, dass sich in den Schriften Horkheimers auch vor dem perhorreszierten Spiegel-Interview vielfach theologische Überlegungen finden, auch in der Kooperation mit Adorno, weshalb sich die verbreitete Auffassung von einer theologischen Wende im Alter einer mangelnden Kenntnis werkimmanenter Kontinuitäten zuschreiben lässt. In diesem Sinn notiert Matthias Lutz-Bachmann: „Wenn Horkheimers letzte Schaffensperiode vielleicht auch deutlicher als frühere mit dem Gegenstand der Religion befasst ist, so kann doch umgekehrt gezeigt werden, dass die Religionsproblematik schon mit den Schriften der dreißiger Jahre eng verbunden ist. [...] Damit verlieren die Ausführungen zur Frage der Religion beim späten Horkheimer den Charakter des Sensationellen, den sie zu Unrecht in der Publizistik der siebziger Jahre zugedacht bekommen haben. “12 Es gibt überdies guten Grund, die affirmative Haltung zur Religion

10 Eitler (2009), 128. Eine materialreiche Dokumentation der Diversität der Reaktionen bietet „Teil II. ,Vom atheistischen Marxisten zum Transzendenz ahnenden Nicht-Marxisten“ - der sogenannte ,Streit um Max Horkheimer““, in: ebd., 119-235.

11 Horkheimer (1970). Aus dieser Ausgabe wird im Folgenden mit in Klammern gesetzten Zahlen zitiert.

12 Lutz-Bachmann (1986), 108. Dieser Aufsatz sucht anhand einer chronologischen Interpretation aufzuzeigen, „dass Horkheimers Verständnis von Religion in den Grundlinien durchaus Kon- 
bis in die frühesten Schriften Horkheimers zurückzuverfolgen, insbesondere zur Novelle „Sehnsucht“ von $1915^{13}$, wobei freilich die Frage, ob bzw. wie weit sich Horkheimers Verständnis von Religion verändert hat, im Auge zu behalten ist. ${ }^{14}$ (Von einigen Elementen dieser gedanklichen Zusammenhänge wird hier die Rede sein.) Einen wichtigen Hinweis gab Horkheimer selbst 1972, als er den Vorwurf der Konversion auf folgende Weise erwiderte: „Eine Wende in dem Sinn, daß ich mir selbst widersprochen hätte, vermag ich nicht zu sehen. “15

Die These von der „Rückkehr“ kann, zweitens, so gedeutet werden, dass sie eine erneute Besinnung auf die jüdische Religion, die Horkheimer seit seiner Kindheit vertraut war, indiziert. Diesbezügliche Fragen seiner Interviewpartner greift Horkheimer gerne auf, wie etwa die eingangs zitierte Passage belegt. Freilich gilt es auch in diesem Fall, simplifizierende Deutungen zu vermeiden. Horkheimer spricht hier nicht als jemand, der von seiner spirituellen Biographie erzählt, sondern bleibt auf dem Boden der Theoriebildung; zu sondieren ist demnach, auf welche Weise die zitierten Glaubenslehren jeweils mit der Kritischen Theorie verknüpft werden. ${ }^{16}$ Wenn Horkheimer sich auf zentrale Überzeugungen des Judentums beruft, geschieht dies in der Intention, einsichtig zu machen, dass es in der Gegenwart darauf ankommt, diese Lehren im philosophischen Kontext zu rekonstruieren. Dies trifft auch auf manche seiner Ausführungen zum Christentum zu. Dieses Vorhaben läuft jedoch, wie er betont, nicht auf eine Säkularisierung religiöser Inhalte hinaus, sondern auf ihre gedankliche Durchdringung - „Religion kann man nicht säkularisieren, wenn man sie nicht aufgeben will“ (68). (Dass sein Denken in dieser Hinsicht einen anderen Weg einschlägt als später das Habermas’sche, wird hier zu thematisieren sein.)

Die These von der „Rückkehr“ kann, drittens, im Sinn einer erneuten Anknüpfung an Autoren der Philosophiegeschichte, die für Horkheimer in früheren

tinuität aufweist“ (ebd., 108). Lutz-Bachmann verweist insbesondere auf Horkheimers kurzen Text aus dem Jahr 1935: „Gedanke zur Religion“, in: Horkheimer (1988), Bd. 3, 326-328.

13 Horkheimer (1988), Bd. 1, 135-141. Für die heutige Auseinandersetzung mit dem durch das Spiegel-Interview ausgelösten „Streit“ ist freilich relevant, wie Eitler betont, dass 1970 nicht alle früheren Schriften Horkheimers publiziert bzw. bekannt, waren; vgl. Eitler (2009), 53 u. 57.

14 Signifikante Diskontinuitäten im Religionsbegriff zeigt Schmidt (1986).

15 Horkheimer fuhr an dieser Stelle fort: „Die Behauptung, mein Denken hätte sich verändert, ist nur insofern richtig, als meine jeweiligen Absichten, die letzten Endes aus derselben tiefen Überzeugung stammen, je nach Situation [...] sich geändert haben, aber nicht die ursprünglichen Gedanke und Gefühle“ (Horkheimer, Das Schlimme erwarten und doch das Gute versuchen, in: ders. 1988, Bd. 7, 463-464).

16 Für eine eingehende Erkundung dieses Themas vgl. Rosen (1995), Kap. „Horkheimers Auffassung des Judentums“, 144-153. 
Phasen seines Denkens ausschlaggebend waren, gedeutet werden. Im Interview sind insbesondere Bezüge zu Kant und Schopenhauer hervorgehoben. Kommentare zum philosophiegeschichtlichen Hintergrund des Horkheimer'schen Werks stellen diese Bezüge häufig im Sinn eines Weges von Kant zu Schopenhauer dar, insbesondere im Sinne eines Fortschreitens von der Konzeption des kategorischen Imperativs zu der des Mitleids, was zur Folge hatte, dass Horkheimers Schopenhauer-Rezeption größere Aufmerksamkeit gefunden hat. ${ }^{17}$ Eingehende Werkanalysen zeigen freilich, dass dieser Weg nicht in einem linearen Sinne als Abkehr zu deuten ist: „Kant ist in seinem Denken allgegenwärtig“18 urteilt etwa Herbert Schnädelbach mit Bezug auf Horkheimers Moralphilosophie. Doch wie verhält es sich hinsichtlich der auf „Sehnsucht“ begründeten Theologie? Bedenkt man, dass Horkheimer sich mit einer Studie über die Kritik der Urteilskraft habilitiert hat ${ }^{19}$ - nachdem bereits seine Dissertation diesem Werk gewidmet war ${ }^{20}$-, liegt es nahe zu fragen, ob die These von der „Rückkehr“ eine intensivierte Rückbesinnung auf Kants Konzeption des „moralischen Beweises“ implizieren könnte, bzw. wie weit eine solche Re-Lektüre Niederschlag gefunden haben mag, auch dort, wo Kant nicht explizit zitiert wird. Dieser Frage gehen die folgenden Überlegungen nach, die durch das Anliegen bestimmt sind, Tiefenstrukturen der Horkheimer'schen Reflexionen zu erkunden, um auf diese Weise die mögliche Relevanz der These von der „Sehnsucht nach dem ganz Anderen“ im Blick auf die heutige Debatte zu verdeutlichen. Dabei gilt es u. a. zu thematisieren, dass es irreführend ist, wenn von Kant inspirierte Reflexionen Horkheimers ohne nähere Begründung mit dem von Schopenhauer entlehnten Begriff „Pessimismus“ charakterisiert werden.

17 Vgl. z. B. Reijen (1982). Helmut Gumnior und Rudolf Ringguth erwähnen die beiden Qualifikationsarbeiten Horkheimers gewissermaßen im Vorübergehen, ohne nach deren möglichen Nachwirkungen, speziell im Spätwerk, zu fragen. Sie schreiben u. a.: „[1925] habilitierte sich Horkheimer mit einer Arbeit über Kants Kritik der Urteilskraft als Bindeglied zwischen theoretischer und praktischer Philosophie. Es war eine rein akademische Arbeit, die sicherlich auch in Rücksicht auf die starke Position den Neukantianismus an den deutschen Universitäten geschrieben worden war. Auch die erste Vorlesung, die Horkheimer als Privatdozent im Wintersemester 1925/26 hielt, beschäftigte sich mit der Philosophie Kants. Der Einfluß seines Lehrers Cornelius war unverkennbar“ (Gumnior/Ringguth 1973, 27). Wo die beiden Autoren mit Bezug auf ,die Sehnsucht, von der Horkheimer im Alter immer wieder gesprochen hat“, von „Horkheimers theologia occulta“ sprechen, „die weder negative Theologie in strengem Verstande, noch gar dogmatisch-positiv ist“ (ebd., 131), wäre wohl ein Rückblick auf die Habilitationsschrift aufschlussreich gewesen.

18 Schnädelbach (1986), 56.

19 Horkheimer (1925).

20 Ders. (1922). 


\section{„Diese Sehnsucht gehört zum wirklich denkenden Menschen“}

Signifikant ist, an welchem Punkt Horkheimers Überlegungen ansetzen: Er geht davon aus, dass die „Sehnsucht nach dem ganz Anderen“ in allen einzelnen Menschen angelegt ist. Dies wird dadurch unterstrichen, dass er auch denjenigen, die sich selbst als Atheisten bezeichnen, unterstellt, diese Sehnsucht zu teilen. Auch für Atheisten, hält er fest, sei der Gedanke, es könne keinen letzten Sinn geben, schmerzlich; auch sie hätten die Sehnsucht, „dass der Mörder nicht über das unschuldige Opfer triumphieren möge“ (62) ${ }^{21}$. Darin kündige sich eine „Theologie der Hoffnung“ an, getragen von der Idee, „dass es bei diesem Unrecht, durch das die Welt gekennzeichnet ist, nicht bleibe, dass das Unrecht nicht das letzte Wort sein möge“ (61). Freilich bedeute dies nicht einen - mehr oder weniger unreflektierten - Überstieg in eine religiöse Überzeugung. „Das Bewusstsein unserer Verlassenheit, unserer Endlichkeit ist kein Beweis für die Existenz Gottes, sondern es kann nur die Hoffnung hervorbringen, dass es ein positives Absolutes gibt“ (56). Doch selbst dieser nicht klar konturierten Hoffnung spricht Horkheimer praktische Relevanz zu: „Auf Gott können wir uns nicht berufen. Wir können nur handeln mit dem inneren Gefühl, dass es einen Gott gibt“ (72).

Wesentliche Elemente dieses Gedankengangs finden sich auch bei Kant, wie nun anhand einiger Kongruenzen gezeigt werden soll. Dabei ist im Allgemeinen zu bedenken, dass „Hoffnung“ eine Schlüsselkategorie der Religionsphilosophie Kants darstellt, die überdies, näher betrachtet, den systematischen Anspruch seines gesamten Werkes zum Ausdruck bringt. ${ }^{22}$ Die grundlegende Weichenstellung Kants greift Horkheimer mehrfach explizit auf, wie u. a. die soeben zitierten Textstellen belegen: die Zurückweisung aller Versuche einer theoretischen Beweisführung. Kant demonstriert ja - in Auseinandersetzung mit den überlieferten Formen von Gottesbeweisen -, dass mittels der theoretischen Erkenntnis bzw. der Logik kein stringenter Beweis für die Existenz Gottes erbracht werden kann, um dann das Thema Religion von der praktischen Vernunft her aufzurollen.

21 Uwe Justus Wenzel hält fest: „Wenn es ein zentrales - wiewohl zeitweise verborgenes - Motiv des Horkheimerschen Werkes gibt, dann das der Sehnsucht. [...] Sonst hätte er die zwischen 1914 und 1918 zu Papier gebrachten, ungestüm expressiven Novellen und Notizen nicht noch wenige Monate vor seinem Tod (1973) unter dem Titel ,Aus der Pubertät‘ erstmals der Öffentlichkeit übergeben“; Wenzel (1995), 38; vgl. auch: Max Horkheimer, Aus der Pubertät. Novellen und Tagebücher, in: Horkheimer (1988), Bd. 1, 17-362. Wenzel geht freilich den philosophischen Implikationen des Begriffs „Sehnsucht“ bei Horkheimer nicht nach.

22 Dazu vgl. Nagl-Docekal (2020, i. E.). 
So hält er in der Vorrede zur zweiten Auflage der Kritik der reinen Vernunft fest: „Ich musste also das Wissen aufheben, um zum Glauben Platz zu bekommen“ ${ }^{23}$. Wenn Kant im Weiteren darlegt, worin die ,in moralischer Absicht hinreichenden Beweisgründe“ ${ }^{24}$ bestehen, macht er geltend, dass die eigentliche Beweisführung von der in jedem Menschen angelegten praktischen Vernunft selbst geleistet wird, wenn auch in zunächst unartikulierter Weise. Demgemäß schreibt er der Philosophie die sekundäre Aufgabe einer Rekonstruktion zu, die darauf abzielt, diese unmittelbare Einsicht auszubuchstabieren und damit zu präzisieren. So argumentiert Kant in der Kritik der Urteilskraft: „Dieser moralische Beweis ist nicht etwa ein neu erfundener, sondern allenfalls nur ein neu erörterter Beweisgrund; denn er hat vor der frühesten Aufkeimung des menschlichen Vernunftvermögens schon in demselben gelegen. “25 Um diese Anfänge plausibel zu machen, fährt er hier fort: „Sobald die Menschen über Recht und Unrecht zu reflektieren anfingen, [...] musste sich das Urteil unvermeidlich einfinden: dass es im Ausgange nimmermehr einerlei sein könne, ob ein Mensch sich redlich oder falsch, billig oder gewalttätig verhalten habe, wenn er gleich bis an sein Lebensende, wenigstens sichtbarlich, für seine Tugenden kein Glück, oder für seine Verbrechen keine Strafe angetroffen habe. Es ist: als ob sie in sich eine Stimme wahrnähmen, es müsse anders zugehen. [...] Nun mochten sie die Art, wie eine solche Unregelmäßigkeit (welche dem menschlichen Gemüt weit empörender sein muss als der blinde Zufall, den man etwa der Naturbeurteilung zum Prinzip unterlegen wollte) ausgeglichen werden könne, sich auf mancherlei noch so grobe Weise vorstellen: so konnten sie sich doch niemals ein anderes Prinzip der Vereinigung der Natur mit ihrem inneren Sittengesetze erdenken, als eine nach moralischen Gesetzen die Welt beherrschende oberste Ursache.“26

Festzuhalten wäre also, dass Kants Philosophie der Religion bei den Einzelnen ansetzt, und nicht - wie oft fälschlich unterstellt wird - von bestimmten, historisch gewachsenen Bekenntnissen ausgeht, um einige ihrer Lehren in das philosophische Denken der Aufklärung zu transponieren. Kant sucht vielmehr die gemeinsame Wurzel aller Religionen zu erkunden: Wie kommt es, so könnte sich seine Ausgangsfrage transkribieren lassen, dass die gesamte Weltgeschichte hindurch menschliche Gemeinschaften ihre Praxis an religiösen Vorstellungen (die in den konkreten Inhalten freilich weit voneinander unterschieden waren) orientiert haben? Unter dieser Perspektive sondiert Kant, wie Religion im Men-

23 Kant (1963e), 33 (im Folgenden zit. als RV).

$24 \mathrm{RV}, 35$.

25 Kant (1963f), 586 (im Folgenden zit. als KU).

$26 \mathrm{KU}$, 586-587. 
schen als solchem verankert ist. Da er die Menschen anthropologisch als vernunftbegabte Naturwesen bestimmt, richtet sich sein Augenmerk auf den Ort der Religion in der Vernunft.

Bedenkt man, dass Horkheimer der Vernunftkonzeption Kants nachdrückliche Vorbehalte entgegenbringt, so erscheint es beachtenswert, dass er seinen Begriff der „Sehnsucht“ im Denken verankert - etwa, wenn er formuliert: „Diese Sehnsucht gehört zum wirklich denkenden Menschen“27. Damit ist gesagt, dass die Sehnsucht, die hier gemeint ist, nicht eine individuelle, wandelbare Gestimmtheit darstellt, sondern eine aus dem Denken erwachsende Haltung, die sich dann einstellt, wenn Menschen sich mit eklatanten Ungerechtigkeiten, mit denen sie konfrontiert sind, „wirklich denkend“ auseinandersetzen. Auf solche Art im Denken verankert, ist diese Sehnsucht als eine geteilte bestimmt. Als geteilt erscheint auch der Sinn für Gerechtigkeit, an dem sich die Denkenden orientieren, wenn sich ihre moralische Entrüstung formiert. So erhebt sich die Frage, wie weit Horkheimer sich hier, ungeachtet seiner Bedenken hinsichtlich der Systematik Kants, an dessen Begriff der praktischen Vernunft annähert. Näherhin lautet diese Frage, wie weit Horkheimers Konzeption der „Sehnsucht des wirklich denkenden Menschen“ von Kants These vom „Bedürfnis der praktischen Vernunft“ als Ursprung der Religion inspiriert sein könnte.

An dieser Stelle empfiehlt es sich, Kants Argumentation genauer zu betrachten. Den Ausgangspunkt bildet die These, dass das Grundprinzip der Moral in der Vernunft angelegt ist, und zwar in der Art, dass wir uns mit einer unbedingten Pflicht konfrontiert finden. In seiner Theorie des „kategorischen Imperativs“ erläutert Kant dieses für den Menschen unumgehbare Bewusstsein von Verpflichtung, wobei er eine signifikante Spannung aufzeigt: Sofern wir zu den Lebewesen gehören, teilen wir die Ausrichtung auf Selbsterhaltung und das eigene Wohlergehen, die sich in reflektierter Form im Streben nach Glück manifestiert (Kant gebraucht in der Regel den Ausdruck „Glückseligkeit“); sofern wir vernunftbegabte Wesen sind, ist in uns zugleich das Bewusstsein angelegt, dass die moralische Pflicht den Charakter der Unbedingtheit hat und uns somit abverlangen kann - und de facto in vielen Situationen abverlangt -, dem eigenen Glücksstreben zuwider zu handeln. Diese Spannung bringt mit sich, wie Kant zeigt, dass sich die Frage nach dem Sinn des menschlichen Lebens in radikaler Weise stellt. Da eine Handlungsweise, in der wir versuchen, der moralischen Pflicht möglichst konsequent gerecht zu werden, nicht selten für uns nachteilige oder schmerzliche Folgen nach sich zieht, kann sich ein Eindruck von Absurdität einstellen. Wir finden uns dann ja in der Lage vor, „der Glückseligkeit bedürftig, ihrer auch

27 Der Spiegel (1970), 81. 
würdig, dennoch derselben nicht teilhaftig zu sein“28. Dieses Konsistenzproblem macht sich auch in einer umfassenderen Perspektive geltend: Kann es sein, dass in dem sich so wohlgeordnet darstellenden Kosmos in Form des Menschen ein Bruch auftritt, der den gesamten Eindruck von Ordnung unterminiert? Selbst „für die unangebauteste Vernunft, sofern sie sich als praktisch betrachtet," so Kant, stellt sich die Frage nach dem Sinn des Lebens der Menschen, ,weil ein als Pflicht aufgegebener Endzweck in ihnen, und eine Natur ohne allen Endzweck außer ihnen, in welcher gleichwohl jener Zweck wirklich werden soll, im Widerspruche stehen". ${ }^{29}$

Hier springt ins Auge, dass die Frage nach dem „Sinn“ des Lebens, die als Titel für das Spiegel-Interview gewählt wurde, bei Kant den Einstieg in die Religionsphilosophie markiert. Auch darin, dass diese Frage aus der für Menschen unumgehbaren Dimension der Moral entspringt, besteht offenkundig Übereinstimmung. Im Speziellen ist zu beachten, dass in der Kritik der Urteilskraft moralische Entrüstung über das Leid, das Unschuldigen von anderen zugefügt wird, als Auslöser der Sinnfrage dargestellt ist - eine Entrüstung, die auf dem „Urteil der moralisch über den Weltlauf reflektierenden Menschenvernunft “30 basiert. Eindrücklich notiert Kant, dass „die Rechtschaffenen [...], unangesehen ihrer Würdigkeit glücklich zu sein, dennoch [...] allen Übeln unterworfen sind“, wie sie durch „Betrug, Gewalttätigkeit und Neid“ verursacht werden, „bis ein weites Grab sie insgesamt (redlich oder unredlich, das gilt hier gleichviel) verschlingt“ und sie so dem „Schlund des zwecklosen Chaos“ überantwortet. ${ }^{31}$ Kant unterstreicht ferner, dass eine konsistente Harmonisierung von Tugend und Glück durch die Menschen selbst nicht bewerkstelligt werden kann - auch nicht mittels der (moralisch gebotenen) fortschreitenden Implementierung von Prinzipien der Gerechtigkeit. Er zeigt dies u. a. im geschichtsphilosophischen Kontext, indem er notiert: „Befremdend bleibt es immer [...]: dass die älteren Generationen nur scheinen um der späteren willen ihr mühseliges Geschäft zu treiben [...], und dass doch nur die spätesten das Glück haben sollen, in dem Gebäude zu wohnen, woran eine lange Reihe ihrer Vorfahren [...] gearbeitet haben. “32 Es ist signifikant, dass Adorno in der unausweichlichen Limitiertheit unserer praktischen Möglichkeiten den eigentlichen Ausgangspunkt von Kants Religionsphilosophie sieht. Mit spezieller Bezugnahme auf die „Konstruktion der Unsterblichkeit als eines

28 Kant (1963d), 238 (im Folgenden zit. als PV).

$29 \mathrm{KU}, 587$.

$30 \mathrm{KU}, 576$.

$31 \mathrm{KU}, 587$.

32 Ders. (1963c), 37. 
Postulats der praktischen Vernunft“ hält er fest: „Dieses Postulat verurteilt die Unerträglichkeit des Bestehenden und bekräftigt den Geist, der sie erkennt. Dass keine innerweltliche Besserung ausreicht, den Toten Gerechtigkeit wiederfahren zu lassen; dass keine ans Unrecht des Todes rührt, bewegt die Kantische Vernunft dazu, gegen Vernunft zu hoffen. Das Geheimnis seiner Philosophie ist die Unausdenkbarkeit der Verzweiflung. “33

Horkheimer folgt also der Argumentationslinie Kants, wenn er festhält: „Die Sehnsucht nach vollendeter Gerechtigkeit [...] kann in der säkularen Geschichte niemals verwirklicht werden; denn selbst wenn eine bessere Gesellschaft die gegenwärtige soziale Unordnung ablösen würde, wird das vergangene Elend nicht gutgemacht“ (69). Dabei greift Horkheimer einen Gedanken auf, den er bereits früh in der Novelle „Wille zur Erkenntnis“ formuliert hatte: Während „vieles Äußerliche gemildert und gebessert werden könne“, heißt es dort, sei doch zu ahnen, „daß alle Besserungen, alle Revolutionen [...] die große Qual nicht berühren würden, weil der Kern des Lebens selbst Qual und Schmerz ist.“34 Dass Horkheimer mit Kants Reflexionen über den „Weltlauf“ übereinstimmt, wurde vielfach auf eine „pessimistische“ Wendung seiner Sichtweise zurückgeführt. (So fragt z. B. Helmut Gumnior Horkheimer danach, „wie es zu seiner Wandlung vom revolutionären Optimisten zum Pessimisten gekommen sei“35.) Mit dieser Deutung ist jedoch außer Sicht gebracht, dass Horkheimers Konzeption der „Sehnsucht“ nicht von einer resignativen Stimmungslage kündet, sondern das in allen Einzelnen angelegte Potenzial zur Transzendierung der Grenzen des im „Weltlauf“ Möglichen thematisiert. Der springende Punkt ist, dass Horkheimer sich nicht auf eine bis heute gängige Auffassung festlegen lässt, die sich so transkribieren lässt: Dass es, wie Kant klar demonstriert, keinen zwingenden Beweis für die Existenz Gottes gibt, bedeutet, dass hinsichtlich der Religion überhaupt keine geteilte Einsicht möglich ist. Das Thema Religion sei somit den je besonderen Lehren und Praktiken der diversen, historisch gewachsenen Glaubensgemeinschaften, bzw. der individuell generierten „Bricolage“ spirituell ausgerichteter Personen, zuzuordnen. Diese Auffassung weist - gewissermaßen mit einem Federstrich - den gesamten Gedankengang, der in Kants Konzeption der „reinen moralischen Religion“ ausgeführt ist, zurück, in der Regel im Zeichen der These, es handle sich dabei um ein Residuum vormoderner Metaphysik. Doch darauf lässt Horkheimer sich nicht ein; er geht vielmehr davon aus, dass in den „wirklich denkenden Menschen“ eine geteilte grundlegende „theologische“ Überzeugung verankert ist, unabhängig

33 Adorno (1970), 376. Dazu vgl. Nagl (2010), 28.

34 Horkheimer (1988), Bd. 1, 172-173.

35 Gumnior, H., Vorwort, in: Horkheimer (1970), 5. 
davon, ob sie einer Glaubensgemeinschaft angehören oder nicht, respektive ob sie sich als religiös oder als atheistisch gesinnt verstehen. Er richtet dabei den Fokus auf die spezifische Art des Denkens, die aus der moralischen Urteilskompetenz erwächst. Aus diesem Blickwinkel weist er nicht nur marxistisch-ideologische, sondern auch szientistische Formen der Religionskritik zurück.

Dem entspricht eine Bemerkung im L'Espresso aus dem Jahr 1969, die als Motto für das Buch Die Sehnsucht nach dem ganz Anderen gewählt wurde: „Für die jungen Leute von heute ist allein die Wissenschaft wahr, weil sie das Wahre mit dem Exakten verwechseln und daran glauben, dass die einzige Gestalt der Vernunft die ist, die ich instrumentell nenne - und dass sie alle anderen aufhebt. “36 Von hier aus scheint es legitim näher zu verfolgen, wie weit Horkheimers theologische Ausführungen an die ,praktische Vernunft“ Kants anknüpfen.

\section{„Eine Theologie der Hoffnung“}

Knapp zusammengefasst, erläutert Kant den Ort der Religion in unser Vernunft auf folgende Weise $^{37}$ : Indem wir Menschen die Vermittlung von Tugend und Glückseligkeit als das „höchste Gut“ betrachten, von dem wir freilich zugleich wissen, es nicht von uns aus herbeiführen zu können, regt sich in uns ein „Bedürfnis“: Dem Eindruck der Sinnlosigkeit tritt das „Bedürfnis der reinen Vernunft“38 nach einer Realisierung des höchsten Guts, die nicht geschichtsimmanent zu erwarten ist, entgegen. Kant erläutert die immanente Logik dieses Bedürfnisses: „Es ist Pflicht, das höchste Gut nach unserem größten Vermögen wirklichzumachen; daher muss es doch auch möglich sein; mithin ist es für jedes vernünftige Wesen in der Welt auch unvermeidlich, dasjenige vorauszusetzen, was zu dessen objektiver Möglichkeit notwendig ist.“" ${ }^{39}$ Demnach ist es das Bedürfnis der Vernunft, „eine oberste Intelligenz“ anzunehmen, „um dem Begriffe vom höchsten Gut objektive Realität zu geben, d. i. zu verhindern, dass es zusamt der ganzen Sittlichkeit nicht bloß für ein bloßes Ideal gehalten werde, wenn dasjenige nirgends existiere, dessen Idee die Moralität unzertrennlich begleitet“.40 Dieses

36 Horkheimer (1970), 7.

37 Zwar verhält es sich so, dass in verschiedenen Schriften Kants jeweils andere Akzentuierungen seiner Argumentation vorliegen, doch kann dies im Folgenden unberücksichtigt bleiben, da es darum geht, die Grundlinie nachzuzeichnen.

$38 \mathrm{PV}, 276$.

39 PV, 278.

40 Kant (1963i), 274 (im Folgenden zit. als DO). 
Bedürfnis ist also nicht von der Art, die alltagssprachlich als „frommer Wunsch“ bezeichnet wird; es begründet vielmehr die „moralische Gewissheit“, dass wir, „ein Dasein Gottes und ein künftiges Leben glauben“ “11 dürfen. Kant unterstreicht die Differenz zwischen „logischer“ und „moralischer“ Gewissheit: Die auf das Bedürfnis der Vernunft gegründete Überzeugung „ist nicht logische, sondern moralische Gewissheit, und da sie auf subjektiven Gründen (der moralischen Gesinnung) beruht, so muss ich nicht einmal sagen, es ist moralisch gewiss, dass ein Gott sei [...], sondern: ich bin moralisch gewiss usw. Das heißt: der Glaube an einen Gott und eine andere Welt ist mit meiner moralischen Gesinnung so verwebt, dass, so wenig ich Gefahr laufe, die letztere einzubüßen, ebensowenig besorge ich, dass mir der erstere jemals entrissen werde könne. “42 Der eingehenden Erläuterung dieser These ist bekanntlich Kants Konzeption der „Postulate der reinen praktischen Vernunft“ gewidmet, die die immanente Logik der Postulate der „Unsterblichkeit der Seele“, der „Freiheit“ und des „Daseins Gottes“ einsichtig zu machen sucht. ${ }^{43}$ „Diese Postulate“, betont Kant, „sind nicht theoretische Dogmata, sondern Voraussetzungen in notwendig praktischer Rücksicht“". ${ }^{44}$

Es gilt zu beachten, worauf Kant hier abzielt: Er sucht den spezifischen Charakter von Religion, wie wir ihn auch in der Alltagssprache verstehen, philosophisch zu benennen: Wir beziehen den Begriff „religiöser Glaube“ üblicherweise weder auf ein theoretisches Wissen (wir betrachten Ungläubige nicht als Personen, denen es an logischem Denken ermangelt) noch auf eine bloße Meinung, die eine Angelegenheit individuell variabler Auffassungen wäre. Die Erläuterung der spezifisch-moralischen Gewissheit erlaubt zugleich, die Bedeutung von Religion als tragendes Fundament der praktischen Orientierung aufzuweisen: Könnte ich nicht der Realisierbarkeit des ultimativen Ziels gewiss sein, hätte dies zur Folge, dass „meine sittlichen Grundsätze selbst umgestürzt werden würden, denen ich nicht entsagen kann, ohne in meinen eigenen Augen verabscheuungswürdig zu sein““45. Demgemäß hält Kant fest, „es ist moralisch notwendig, das Dasein Gottes anzunehmen“"46.

Mit dem Begriff Religion ist hier die von allen Menschen geteilte Überzeugung gemeint, die Kant als die „natürliche Religion“ ${ }^{“ 47}$ bezeichnet. Diese liegt, wie er

$41 \mathrm{RV}, 693$.

$42 \mathrm{RV}, 693-694$.

$43 \mathrm{PV}, 252-287$.

$44 \mathrm{PV}, 264$.

$45 \mathrm{RV}, 693$.

46 PV, 256. Auf ähnliche Weise formuliert Kant: „Moral [...] führt unumgänglich zur Religion“ (ders., 1963h, 652; im Folgenden zit. als RG).

47 RG, 824. 
erläutert, allen bestimmten Bekenntnissen zugrunde: „Alle Religion gründet sich auf Theismus moralis“" ${ }^{48}$. Während die unterschiedlichen Bekenntnisse, die im Lauf der Geschichte entstanden sind, jeweils nur für einen bestimmten Kreis von Gläubigen Überzeugungskraft hatten bzw. haben - Kant verwendet häufig den Ausdruck „Kirchenglauben“49 -, ist die „natürliche Religion“, die das Wesentliche aller Religion erfasst, in jedem Menschen angelegt. Sie ist „,allgemein mitteil-

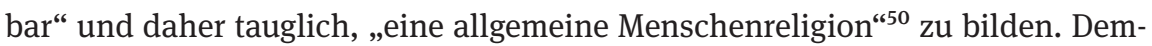
gemäß lautet Kants These: „Es ist nur eine (wahre) Religion; aber es kann vielerlei Arten des Glaubens geben. “51 Bezugnehmend auf die Verankerung in der reinen praktischen Vernunft bezeichnet Kant diese eine Religion als „reinen Religionsglauben“: „Der reine Religionsglaube“ ist der, „welcher [...] ein bloßer Vernunftglaube ist, der sich jedermann zur Überzeugung mitteilen lässt"552. Aus dieser Perspektive verliert die übliche Unterscheidung von Gläubigen und Ungläubigen an Plausibilität: Kant verteidigt seine These, wonach es im Grunde genommen keinen Menschen ohne Religion gibt, explizit mit Blick auf diejenigen, die sich als Atheisten bezeichnen, indem er auf die Differenz zwischen Theorie und Praxis verweist: Auch wer agnostische Theorien vertritt, vertraut im Handeln darauf, dass es nicht sinnlos ist, dem moralischen Imperativ zu folgen. „Der Atheismus kann in der puren Speculation sein, aber in der praxi kann ein solcher ein Theist oder ein Verehrer Gottes seyn; dessen Irrtum erstreckt sich auf die Theologie und nicht auf die Religion“"53. Wie Allen Wood hervorhebt, führt Kant diese These mitunter auf eine zurückhaltendere Art aus: „The ,minimum of theology“, he says, is not that God exists but only that God is possible. [...] Devoted pursuit of one's final moral end might be better served by a confidence that the highest good will at last be attained, but the bare minimum reason requires is belief that it is possible of attainment. Hence Kant thinks that morality is compatible with a hopeful agnosticism about God's existence, even though something stronger than this would be preferable. [...] Only the minimum cognition (it is possible that there is a God) has to be subjectively sufficient [...]. I can have religion in this sense even if I am an agnostic"54.

48 Ders. (1900 ff.), Bd. 28, 1141.

$49 \mathrm{RG}, 762$.

$50 \mathrm{RG}, 824$.

$51 \mathrm{RG}, 768$.

$52 \mathrm{RG}, 762$.

53 Ders. (2004),125. Allen W. Wood erläutert: „What moral arguments show is that morally disposed people are involved in a kind of practical irrationality unless they believe in a future life and a providential and gracious Deity“ (Wood 1992, 404).

54 Ebd., 405-406. Wood bezieht sich hier auf RG, 822. 
Vor dem Hintergrund dieser Differenzierungen Kants treten nun Parallelen sowie Divergenzen zwischen Horkheimer und Kant deutlicher hervor. Zum einen sind einige Kongruenzen offenkundig, wie in der zitierten These Horkheimers: „Alles, was mit Moral zusammenhängt, geht logisch letzten Endes auf Theologie [...] zurück“ (80), oder auch in seiner bereits 1963 publizierten Auffassung, wonach der Theismus unverzichtbar sei, wenn es gelte, in der kritischen Auseinandersetzung mit dem zunehmend dominierenden Positivismus „einen unbedingten Sinn“ zu bewahren. ${ }^{55}$ Doch zeigt sich zum anderen, dass die Konzeptionen „Sehnsucht“ und „Bedürfnis der praktischen Vernunft“, ungeachtet ihres geteilten Ausgangspunkts in der moralischen Entrüstung über das Leid Unschuldiger, nicht deckungsgleich sind. Wie es scheint, erhebt Kants Gedanke des dem „Bedürfnis der praktischen Vernunft“ entspringenden „moralischen Beweises“ für Horkheimer immer noch zu viel an Beweisanspruch. Orientiert man sich an seinen explizit geäußerten Vorbehalten, so gibt es seines Erachtens auch keine „moralische Gewissheit“ hinsichtlich der Existenz Gottes und eines künftigen Lebens; dies ist, wie er betont, die Pointe der zurückhaltenden Konzeption der „Sehnsucht nach dem ganz Anderen“. Zu überlegen ist freilich, was es bedeutet, dass Horkheimer dieser nicht klar konturierten Einstellung praktische Relevanz zuspricht: „Auf Gott können wir uns nicht berufen. Wir können nur handeln mit dem inneren Gefühl, dass es einen Gott gibt“ (72). Man stößt hier auf eine immanente Spannung: Wenn es zutrifft, dass Menschen, die ihr Handeln an moralischen Prinzipien orientieren, von einem innerlichen Vertrauen auf ein letztlich eintretendes Sinnganzes getragen sind, dann stellt sich das ersehnte „ganz Andere“, obwohl es sich einer explizierbaren Erfassung entzieht, nicht als völlig unbestimmt dar. Der gesamte Aufbau von Horkheimers Überlegungen orientiert sich ja an der Vorstellung von Gott als oberster Instanz der Gerechtigkeit, von der Erlösung aus unschuldigem Leid zu erwarten ist. ${ }^{56}$ Genauer betrachtet, impliziert dies spezifischere Vorstellungen: nicht nur die der Allmacht, sondern auch die der Allwissenheit. Die letztere ist ja z. B. in der Annahme vorausgesetzt, Gott nehme alles Leid, das Unschuldigen zugefügt wurde, wahr.

Mit der Art von immanenter Spannung, die sich so bei Horkheimer zeigt, hat Kant sich auseinandergesetzt, wobei sich zwei Denkschritte abzeichnen. Kant

55 Vgl. Horkheimer, Theismus - Atheismus, in: ders. (1988), Bd. 7, 173-186.

56 Die bei Horkheimer zentrale Hoffnung auf Gottes Gerechtigkeit bleibt unberücksichtigt, wenn Papst Benedikt XVI. in der Enzyklika Spe salvi von 2007 schreibt: „Horkheimer hat radikal bestritten, dass irgendein immanenter Ersatz für Gott gefunden werden könne, zugleich freilich auch das Bild des guten und gerechten Gottes abgelehnt“ (Spe salvi, Nr. 42). Dazu vgl. Eitler (2009), 354-355. 
vertritt zunächst die These, dass die Vorstellung von Gott als „höchste moralische Instanz" notwendig eine Reihe von bestimmten Eigenschaften impliziert. Demnach muss der „oberste Wille [...] allgewaltig sein, damit die ganze Natur und deren Beziehung auf die Sittlichkeit in der Welt ihm unterworfen sei; allwissend, damit er das Innerste der Gesinnungen und ihren moralischen Wert erkenne; allgegenwärtig, damit er unmittelbar allem Bedürfnisse, welches das höchste Weltbeste erfordert, nahe sei; ewig, damit in keiner Zeit diese Übereinstimmung der Natur und Freiheit ermangele“ ${ }^{\text {57 }}$. Besondere Aufmerksamkeit widmet Kant der moralischen Bedeutung der Vorstellung der Allgegenwärtigkeit; er nimmt dabei Bezug auf die biblische Darstellung von Gott als „Herzenskündiger“58, wie sie sich bereits in Jeremias 17,9.10 findet: „Es ist das Herz ein trotzig und verzagtes Ding; wer kann es ergründen? Ich, der Herr, kann das Herz ergründen [...] und gebe einem jeglichen nach seinem Tun, nach den Früchten seiner Werke. “59 - Im zweiten Schritt macht Kant geltend, dass diese Vorstellung von göttlichen Eigenschaften ihre Logik allein aus den Begriffen der menschlichen Praxis bezieht und daher keinen unsere Perspektivität überschreitenden Erkenntnisanspruch erheben kann. Er knüpft dabei an die traditionellen theologischen Konzeptionen analogia entis und via eminentiae an. Dementsprechend unterstreicht er, dass es uns unmöglich ist zu erkennen, wie Gott die Menschen wahrnimmt - es könnte sein, dass sich Gottes Beurteilung der Taten der Einzelnen stark unterscheidet von ,unserer Schätzung, die wir in den Begriffen des Verhältnisses der Ursache und Wirkungen unvermeidlich auf Zeitbedingungen eingeschränkt sind““ ${ }^{60}$ Kant betont jedoch auch, dass dies nicht im Sinne einer Nivellierung des Unterschiedes zwischen Gut und Böse verstanden werden dürfe. ${ }^{61}$

Diese Differenzierungen lassen einsichtig werden, warum Kant im Zuge der Erläuterung der drei Grundfragen der menschlichen Existenz für die dritte Frage die Formulierung „Was darf ich hoffen?“62 wählt. Der Logik der Postulate entspre-

$57 \mathrm{RV}, 684$.

58 Vgl. RG, 720, 758 u. 864. Luther verwendet diesen Ausdruck in seiner Übersetzung der Bibel. Bettina Stangneth weist in ihrem Kommentar zu Kants Religionsphilosophie darauf hin, dass die deutschsprachige Bezeichnung „Herzenskündiger“ im 18. Jahrhundert populär war; vgl. Stangneth (2003), 288.

59 Vgl. auch Apg 15,8: „Gott, der die Herzen kennt“. Für eine eingehendere Untersuchung der Konzeption des „Herzenskündigers“ bei Kant vgl. Nagl-Docekal (2010).

60 RG, 86.

61 „[K]önnte Gott alle Laster vergeben, so könnte er sie auch erlaubt machen [...], alsdann aber wären die moralischen Gesetze etwas Willkürliches“ (Kant 2004, 133). Für eine detaillierte Erkundung der komplexen Implikationen von Kants Gottesbegriff vgl. Byrne (2007).

62 RV, 677. 
chend, indiziert der Ausdruck „hoffen“, dass wir im Blick auf diejenigen unserer Handlungen, die wir für moralisch gerechtfertigt halten, guten Grund haben, die dereinstige Vermittlung von Tugend und Glückseligkeit zu erwarten (wir können „vernünftigerweise hoffen“63), dass es diesbezüglich jedoch keine definitive Aussicht von der Art geben kann, wie sie im Bereich empirisch gestützter Prognosen zulässig ist. Das Verbum „darf“ bringt denn auch zum Ausdruck, dass die ultimative Beurteilung unsere Handlungen nicht bei uns liegt. ${ }^{64}$

Von hier aus gesehen erscheint Horkheimers Abrücken von Kant weniger weitreichend, als er selbst es gesehen haben mag. Vielmehr zeigt sich, dass Kants Differenzierungen herangezogen werden können, um die Konzeption der „Sehnsucht nach dem ganz Anderen“ näher zu durchdenken, so dass die These, wonach nur per negationem von einem „ganz Anderen“ gesprochen werden könne, mit der für die moralisch motivierte Praxis ausschlaggebenden Hoffnung auf „einen guten und allmächtigen Gott“ kompatibel ist.

Beachtenswert scheint in diesem Kontext, wie Adorno in seiner affirmativen Referenz auf Kants Konzeption der „Postulate“ deren ästhetische Bearbeitung in Schillers „Ode an die Freude“ (1786/1803) aufgreift, wo es heißt: „Brüder, überm Sternenzelt muss ein guter Vater wohnen“. Adorno notiert dazu: Kant „hielt an den metaphysischen Ideen fest und verbot dennoch [...], überzuspringen in den Satz, das Absolute sei darum [...], in großartiger Zweideutigkeit hat er seine Position offen gelassen; dem Motiv ,Muss ein ewiger Vater wohnen“, das Beethovens Komposition [...] in Kantischem Geist auf dem Muss akzentuierte, stehen Passagen gegenüber, in denen Kant den Übergang zur Affirmation [verschmäht]“65.

Signifikant ist, dass die auf diese Weise affirmierte Sehnsucht nicht einem bloß negativ gefassten „ganz Anderen“ gilt, sondern einem als gütig vorgestellten Gott. Freilich: Wenn hier vorgeschlagen wird, Horkheimer im Rückgriff auf Kant zu lesen, so ist damit nicht gesagt, die Postulatenlehre würde sich in all ihren systematischen Details in Horkheimers Konzeption abbilden; es sollen lediglich maßgebliche Konvergenzen aufgezeigt werden. $\mathrm{Zu}$ überlegen wäre ja auch umgekehrt, ob es sich in der heutigen Kant-Rezeption als angezeigt erweisen könnte, manche Elemente der kantischen Argumentation auf der Basis der von der Kritischen Theorie artikulierten Erfahrung der Schrecken der totalitären Regime des 20. Jahrhunderts neu zu akzentuieren.

$63 \mathrm{RG}, 722$.

64 Hierzu vgl. Langthaler (2018), 82-83; O’Neill (2003).

65 Adorno (1970), 376. 
Eine wesentliche Übereinstimmung mit Kant liegt auch in der Art, wie die traditionellen Glaubensgemeinschaften aus philosophischer Perspektive eingeschätzt werden. Horkheimer steht auf dem Boden der Aufklärung, wenn er die philosophische Theologie als Instrument der Kritik an verkrusteten dogmatischen Lehren und Praktiken versteht, was er u. a. so zum Ausdruck bringt: „Mögen die alten Konfessionen weiter existieren und wirken in dem Eingeständnis, dass sie eine Sehnsucht ausdrücken und nicht ein Dogma. “66 Diese Sichtweise lässt klare Parallelen zur kantischen erkennen. Zwar rückt Kant eine langfristige Zielsetzung in den Vordergrund, indem er betont, es komme letztlich darauf an, die von allen Menschen geteilte moralische Religion in einer alle Menschen auf immer vereinigenden Kirche $\mathrm{zu}$ implementieren ${ }^{67}$; doch sieht er die unmittelbare Aufgabe darin, die überlieferten Glaubenslehren von ihren unvertretbaren dogmatischen Festlegungen - vom „despotischgebietenden Kirchenglauben“68 - zu befreien. Eine sinnvolle Aneignung erfordere, die vom reinen Religionsglauben vorgegebenen „einschränkenden Bedingungen“ zu berücksichtigen, d. h., „in der Schrift denjenigen Sinn zu suchen, der mit dem Heiligsten, was die Vernunft lehrt, in Harmonie steht. “69 Unter dieser Voraussetzung hält Kant fest, es komme nicht darauf an, dass „,der Kirchenglaube [...] aufhöre (denn vielleicht mag er als Vehikel immer nützlich und nötig sein) ${ }^{\text {“70 }}$.

Wenn Horkheimer, wie Kant, für eine entdogmatisierende Re-Lektüre tradierter Glaubensehren plädiert, so geschieht dies im Blick auf eine Besorgnis erregende Entwicklung: Er geht davon aus, dass (von Verkrustungen befreite) Konfessionen der rettenden Aufrechterhaltung des „Bewusstseins der Endlichkeit“ - welches im zeitgenössischen Kontext verloren zu gehen droht - zu dienen vermögen. Sie können „dem Menschen bewusst machen, dass er ein endliches Wesen ist, dass er leiden und sterben muss; dass aber über dem Leid und dem Tod die Sehnsucht steht, dieses irdische Dasein möge nicht absolut, nicht das letzte sein“(67).

66 Der Spiegel (1970), 81.

67 Dabei geht es, wie Kant erläutert, darum, „das moralische Reich Gottes auf Erden, soviel es durch Menschen geschehen kann“ (RG, 761), zu etablieren.

$68 \mathrm{RG}, 797$.

$69 \mathrm{RG}, 740$.

70 RG, 802. 


\section{„Die Totalverwaltung der Welt“}

Wenn der Begriff „Pessimismus“ auf Horkheimers späte Philosophie angewendet werden soll, so müsste dies in anderer Hinsicht erfolgen als üblich: Nicht seine Konzeption einer „Theologie der Hoffnung“ wäre mit diesem Begriff zu charakterisieren, sondern, im Gegenteil, seine These von dem sich gegenwärtig abzeichnenden Schwinden der „Sehnsucht nach dem ganz Anderen“. Seine eigentliche Brisanz gewinnt das Spiegel-Interview dadurch, dass Horkheimer seine ursprünglich auf die Schrecken der nationalsozialistischen sowie der stalinistischen Herrschaft zugeschnittene Kritik nun gegen eine weitere, heraufziehende Form des Totalitären richtet. In seinem „Brief an den S. Fischer Verlag“ vom 3. Juni 1965 schrieb er, sein zuvor „auf Analyse der Gesellschaft bauender Glaube an fortschrittliche Aktivität schlägt in Angst vor neuem Unheil, vor der Herrschaft allumfassender Verwaltung um““. ${ }^{71}$

Unter den Bedingungen der globalen, alle Lebenssphären zunehmend durchdringenden Logik der kapitalistischen Ökonomie sowie einer dementsprechend durchrationalisierten politischen Ordnung entsteht, so Horkheimer, eine Lage, die als „Totalverwaltung der Welt“ zu charakterisieren ist. „Die immanente Logik der Geschichte, so wie ich sie heute verstehe, führt tatsächlich zur verwalteten Welt. Durch die sich entfaltende Macht der Technik, [...] durch schonungslosen Wettbewerb zwischen den Machtblöcken scheint mir die totale Verwaltung der Welt unausweichlich geworden zu sein. [...] Ich glaube, dass die Menschen dann in dieser verwalteten Welt ihre Kräfte nicht werden frei entfalten können. Sondern sie werden sich an rationalistische Regeln anpassen, und sie werden diesen Regeln schließlich instinktiv gehorchen. Die Menschen dieser zukünftigen Welt werden automatisch handeln“ (83-84). In seinem Werk Kritische Theorie schreibt Horkheimer ähnlich: „Es ist, als ob das Denken selbst auf das Niveau industrieller Prozesse reduziert worden wäre, einem genauen Plan unterworfen kurz, zu einem festen Bestandteil der Produktion gemacht.“72

Gewiss, so Horkheimer einschränkend, „wird die verwaltete Welt auch eine positive Seite haben: Die materiellen Bedürfnisse der Menschen können befriedigt werden“, und „vielleicht können auch [...] Kräfte entfaltet werden, die einen nicht ausschließlich technischen Fortschritt hervorbringen. Zunächst einmal im Hinblick auf die Gerechtigkeit“ (85). Doch letztlich bleibt sein Ausblick düster,

71 Horkheimer (1968), Bd. 2, IX. Zwi Rosen bezieht den Begriff „Pessimismus“ auf Horkheimer, indem er auf dessen Diagnose verweist, wonach „Gerechtigkeit, Gleichheit, Glück, Toleranz [...] ihre geistigen Wurzeln verloren“ haben (Rosen 1995, 135).

72 Horkheimer (1968), Bd. 2, 234. 
und dies kennzeichnet auch seine Überlegungen zur Zukunft der Sehnsucht. Zwar hält Horkheimer zunächst fest: „Die Sehnsucht nach dem Absoluten [...] wird es vielleicht auch in der verwalteten Welt geben. Denn selbst dann, wenn alle materiellen Bedürfnisse befriedigt werden, bleibt die Tatsache, dass der Mensch sterben muss“ (88). Doch werde die Möglichkeit dieser Sehnsucht zunehmend verloren gehen: „Je weiter der Fortschritt, desto gefährdeter nicht nur der Glaube, sondern die wahre Sehnsucht nach einem Besseren. Ebendaher wird alles nicht rein positivistische Denken und Fühlen mehr und mehr zu einem Phänomen der Kindheitsperiode der Menschheit“ (75-76). In der Kritik der instrumentellen Vernunft ist zu lesen: „Im Augenblick ihrer Vollendung ist Vernunft irrational und dumm geworden. Das Thema dieser Zeit ist die Selbsterhaltung, während es gar kein Selbst zu erhalten gibt.“73

Diese These Horkheimers ist als eine klare „Absage an die Aufklärung“ verstanden worden ${ }^{74}$, doch ist der Begriff „Aufklärung“ $\mathrm{zu}$ eng gefasst, wenn er mit einer szientistischen Ausrichtung identifiziert wird. $\mathrm{Zu}$ beachten ist hingegen, dass Überlegungen wie die zuletzt zitierten abermals eine Parallele zu Kant erkennen lassen - man ist an Kants Gedanken zum „Vernunftunglauben“ erinnert. Die Verortung dieses Gedankens in einer Deutung der Aufklärung sei hier knapp rekapituliert. Im Allgemeinen charakterisiert Kant die Aufklärung bekanntlich durch den „Wahlspruch“: „Sapere aude! Habe Mut, dich deines eigenen Verstandes zu bedienen!“75 Die Bedeutung dieses Wahlspruchs macht er dadurch einsichtig, dass er ihn mit der tradierten Anforderung kontrastiert, in allen relevanten Bereichen des Lebens von autoritativ vorgegebenen Lehrsätzen auszugehen, ohne dieselben kritisch zu prüfen. (Kants Beispiele für „die Fußschellen einer immerwährenden Unmündigkeit" ${ }^{\text {"76 }}$ reichen von der Medizin und Theologie über die hierarchische Geschlechterordnung bis zur Gesetzgebung.) Den geforderten Befreiungsschlag aufzugreifen, kann jedoch, wie Kant weiter erläutert, zunächst auf eine Verunsicherung hinauslaufen: „Wer sie [die Fußschellen] auch abwürfe, würde dennoch auch über den schmalesten Graben einen nur unsicheren Sprung tun, weil er zu dergleichen freier Bewegung nicht gewöhnt ist. “77 So sei es u. a. zu einer überzogenen Abkehr gekom-

73 Ders. (1974a), 321.

74 Gumnior, H., Zur Vorgeschichte und aktuellen Situation des Interviews, in: Horkheimer (1970), 38.

75 Kant (1963a), 53, im Folgenden zit. als WA. Für eine eingehende Analyse der kantischen Überlegungen zum Thema „Aufklärung“ vgl. Brandt (2010), Kap. VI: „Kritik und Aufklärung“, $175-213$.

76 WA, 54.

77 Ebd. 
men, die zugleich mit den tradierten Denkvorgaben auch die Prinzipien der Vernunft zurückweist, d. h., sich an der „Maxime eines gesetzlosen Gebrauchs der Vernunft“"78 orientiert. Auf dem Gebiet der Religion sind Kant zufolge die Konsequenzen eines derart überzogenen Gestus der Befreiung besonders schwerwiegend: „Wenn also der Vernunft in Sachen, welche übersinnliche Gegenstände betreffen, als das Dasein Gottes und die künftige Welt, das ihr zustehende Recht, zuerst zu sprechen, bestritten wird, so ist aller Schwärmerei, Aberglauben, ja selbst der Atheisterei eine weite Pforte geöffnet."79

So zeigt Kant eine verhängnisvolle Konstellation auf: Gerade zu dem Zeitpunkt in der Geschichte, in dem das Potential des selbstständigen Denkens erkannt wurde, die gemeinsame moralische Wurzel aller Religionen so auszudeuten, dass alle parochiale Engstirnigkeit überwunden werden könne - gerade zu diesem Zeitpunkt wird die Vernunft torpediert. „Also ist die unvermeidliche Folge der erklärten Gesetzlosigkeit im Denken [...] diese: dass die Freiheit zu denken zuletzt dadurch eingebüßt wird. " ${ }^{80}$ Kant bezeichnet das Ergebnis dieser Wende mit dem Ausdruck „Vernunftunglaube“: „Die Maxime der Unabhängigkeit der Vernunft von ihrem eigenen Bedürfnis (Verzichtung auf Vernunftglauben) heißt nun Unglaube: [...] ein Vernunftunglaube, ein misslicher Zustand des menschlichen Gemüts, der den moralischen Gesetzen alle Kraft der Triebfedern auf das Herz, mit der Zeit sogar ihnen die Autorität benimmt, und die Denkungsart veranlasst, die man Freigeisterei nennt, d. i. den Grundsatz, gar keine Pflicht mehr zu erkennen. [...] Und so zerstört Freiheit im Denken, wenn sie so gar unabhängig von Gesetzen der Vernunft verfahren will, endlich sich selbst. “81 Mit Bezug auf seine Zeit stellt Kant unter dem Titel „Vernunftunglaube“ eine Reihe von Phänomenen zusammen, die auch heute verbreitet sind: Neben dem explizit geäußerten Atheismus nennt er die Auffassung, jeder Einzelne könne sich „nach seinem Belieben" ${ }^{62}$ einen eigenen Glauben zurechtlegen - diesem Glauben fehle freilich jede Bindungskraft. Als eine andere Spielart betrachtet Kant den Aberglauben, den er auf ein Umschlagen der „Schwärmerei“ zurückführt: Wenn ,jetzt jeder seiner Eingebung folgt: so müssen zuletzt aus inneren Eingebungen durch äußere Zeugnisse bewährte Fakta [...], mit einem Worte die gänzliche Unterwerfung der Vernunft unter Facta, d. i. der Aberglaube entspringen. “83 Diesen Arten von Verrat

78 DO, 281.

79 DO, 278.

80 DO, 281.

81 DO, 282. Dem entsprechend hält Kant in einer Reflexion fest, der „Ungläubige verleugnet, dass Moralität für ihn Triebfeder sei“ (Kant 1900 ff., Bd. 17, 503, Refl. 27771).

82 DO, 279.

83 Ebd. 
an der Vernunft entgegenzutreten, stellt für Kant das genuine Anliegen der Aufklärung dar. Die Philosophie hat dabei die Aufgabe, die Wichtigkeit „der Maxime der Selbsterhaltung der Vernunft" in Sicht zu bringen. ${ }^{84}$

Horkheimer scheint Kants Überlegungen zum „Vernunftunglauben“ fortzuschreiben, wenn er für die Zukunft nicht nur das Ende der Theologie, sondern auch das der Philosophie erwartet: „Man wird das Theologische abschaffen. Damit verschwindet das, was wir ,Sinn` nennen aus der Welt. Zwar wird große Geschäftigkeit herrschen, aber eigentlich sinnlose, also langweilige. Und eines Tages wird man auch die Philosophie als eine Kinderangelegenheit des Menschen betrachten. [...] Ernsthafte Philosophie geht zu Ende“ (88-89). Seiner bereits 1947 formulierten These von der „Verfinsterung der Vernunft“ ${ }^{* 55}$ entsprechend, antizipiert Horkheimer ,eine Verrohung des persönlichen und öffentlichen Lebens, so dass sich zum materiellen noch das geistige Elend gesellt“ (70). Er sieht insbesondere die Gefahr eines moralischen Elends, insofern die „Gewissensbildung heute gefährdet ist“ (79). Dass diese Befürchtungen ein halbes Jahrhundert, nachdem sie vorgebracht wurden, als berechtigt erscheinen, ja, sich in mancher Hinsicht bewahrheitet haben, liegt auf der Hand. Umso dringlicher ist die Frage, wie Philosophie respektive Kritische Theorie dieser Entwicklung entgegentreten könnte bzw. sollte. Horkheimer hält dazu fest: „Die wahre gesellschaftliche Funktion der Philosophie liegt in der Kritik des Bestehenden. [...] Das eigentliche Ziel einer derartigen Kritik ist es zu verhindern, dass die Menschen sich an jene Ideen und Verhaltensweisen verlieren, welche die Gesellschaft in ihrer jetzigen Organisation ihnen eingibt“ (82-83). ${ }^{86}$ Um diese Zielsetzung umzusetzen, bedürfe es einer Theorie, die durch ein Insistieren auf „der unabänderlichen Verlassenheit des Menschen“ befähigt ist, „die Gesellschaft vor einem blöden Optimismus, vor dem Aufspreizen ihres eigenen Wissens als einer neuen Religion“ zu bewahren (54), und die zugleich die „vorsichtig“"87 formulierte Perspektive der „negativen Theologie“ eröffnet, wonach ,über dem Leid und dem Tod die Sehnsucht steht, dieses irdische Dasein möge nicht absolut, nicht das letzte sein“ (67). Zu den Elementen einer so verfassten Philosophie gehört auch eine spezifische Theorie der Politik, die einsichtig zu machen sucht, „dass Politik, welche nicht Theolo-

84 DO, 283. Für eine eingehende Studie zu diesen Zusammenhängen vgl. Langthaler (2018).

85 Die 1947 auf Englisch publizierte Schrift „Eclipse of Reason“ (Verfinsterung der Vernunft) bildet in deutscher Übersetzung den ersten Teil des Buches „Zur Kritik der instrumentellen Vernunft"; vgl. Horkheimer (1974a), 11-174.

86 Horkheimer greift hier einen Gedanken wieder auf, den er bereits 1940 in seinem Essay „Die gesellschaftliche Funktion der Philosophie“ formuliert hatte; vgl. ders. (1968), Bd. II, 304.

87 Der Spiegel (1970), 81. 
gie oder Metaphysik, damit natürlich auch Moral, in sich bewahrt, letzten Endes Geschäft bleibe“ ${ }^{88}$.

\section{„Ein theologisches Postulat“}

Obwohl Horkheimers Überlegungen offenkundig in zentralen Weichenstellungen von Anknüpfungen an Kants Religionsphilosophie geprägt sind, blieb dieser Aspekt in der späteren Rezeption vielfach unterbelichtet. ${ }^{89}$ Ein Grund könnte darin liegen, dass Horkheimer selbst, insofern er davon ausgeht, die theologische Perspektive könne heute nur in „vorsichtiger“ Form ausgedrückt werden, einen zweideutigen Eindruck vermittelt. Dies wird insbesondere am Begriff „Sehnsucht“ deutlich: Indem diese Wortwahl suggeriert, es gehe um eine rein emotionelle Dimension, kann sie die Aufmerksamkeit davon ablenken, dass Horkheimers Darlegung seiner Konzeption der „Sehnsucht“ vom „denkenden Menschen“, und damit vom „Bedürfnis der Vernunft“, ausgeht. Folgende Passage des Spiegel-Interviews lässt diesen Kant-Bezug klar hervortreten: „Spiegel: Indem Sie über die [...] Verlassenheit des Menschen sprechen, reden Sie zugleich über das Absolute, also Gott. Ist das nicht ein Gottesbeweis? Horkheimer: Nein. Das ist kein Gottesbeweis. Ich würde sagen, es ist ein theologisches Postulat. "90 Von hier aus wäre zu überlegen, ob vielleicht ein anderer Grund für die verbreitete verkürzte Lesart des Begriffs „Sehnsucht“ darin liegen könnte, dass die Horkheimer-Rezeption sich oft nicht näher auf den argumentativen Aufbau von Kants Konzeption der „Postulate“ - insbesondere in der Unterscheidung von logischen respektive theoretischen Gottesbeweisen - einlässt.

$\mathrm{Zu}$ den rezentesten Auseinandersetzungen mit Horkheimers Überlegungen zur Religion zählen die Referenzen in Jürgen Habermas' Werk Auch eine Geschichte der Philosophie. Horkheimer wird hier aus der Perspektive des „nachmetaphysischen Denkens" betrachtet, wobei Habermas von einer seiner zentralen Thesen ausgeht: „Die Säkularisierung des christlichen Selbst- und Weltverständnisses verschiebt [...] den locus of control von den rettenden Interventionen Gottes auf den Gebrauch, den nun die kommunikativ vergesellschafteten Subjekte selber von ihrer vernünftigen Freiheit machen müssen“; „[e]rnüchternd“ wirke freilich,

88 Ebd., 80.

89 Wo die Kant-Bezüge des horkheimerschen Denkens erörtert werden, geschieht dies in der Regel im Blick auf die Rezeption des „kategorischen Imperativs“ sowie der geschichtsphilosophischen Fortschrittskonzeption.

90 Der Spiegel (1970), 81. 
setzt Habermas hinzu, „das bis dahin unvorstellbare Maß an Verständigungsund Kooperationsbereitschaft, das für die Sammlung der zerstreuten Kräfte erforderlich ist, wenn ein zunehmend inklusives, auf der Grundlage einer diskursiven Willensbildung gerechtfertigtes kollektives Handeln von letztlich globaler Reichweite institutionalisiert werden muss“91. Im Blick auf rezente Entwicklungen notiert Habermas, „die weltanschauliche Substanz des Glaubens“ sei inzwischen weit ,abgemagert [...]. Im Extremfall spitzt die theologische Aufklärung das ,religiöse Weltverhältnis‘ auf den Bezug zu einem anonymen ,Unbedingten` zu. [...] Allerdings wird Gott immer noch als eine rettende Instanz gedacht, die die affirmative Bewältigung eines radikalisierten Endlichkeits- und Kontingenzbewusstseins erlaubt. Gemeint ist [...] eine via negationis bestimmte Gegenmacht, die verspricht, die unausweichlichen Risiken der menschlichen Existenz aufzufangen. Nach dieser Lesart bezieht sich die religiöse Sinngebung auf das Bewusstsein der ,Befristung، unserer Lebenszeit. [So] verspricht die Religion auf die ein- oder andere Weise Versöhnung mit der ultimativen Schwelle des Todes; sie tröstet über die existenziellen Erfahrungen von Schmerz und Krankheit, Not, Einsamkeit und Verzweiflung [...]. Wer freilich die Religion vom nachmetaphysischen Denken nur noch durch eine affirmative Antwort auf die Frage nach der möglichen Akzeptanz der Endlichkeit einer vom Kontingenzbewusstsein geprägten Existenz unterscheiden möchte, lädt zu einem funktionalistischen Verständnis der Religion geradezu ein. Besteht der Sinn von Religion nur in der Bewältigung lebensgeschichtlicher Kontingenzen?"92

In diesem Kontext verweist Habermas ${ }^{93}$ auf seinen 1991 veröffentlichten Kommentar „Zu Max Horkheimers Satz: ,Einen unbedingten Sinn zu retten ohne Gott, ist eitel““94. Darin schreibt er Horkheimer ein „zwiespältiges Verhältnis zur Religion“ zu, das auf eine „tiefe Vernunftskepsis“995 gegründet sei, und gelangt zu folgender Einschätzung: „Am Ende pendeln Horkheimers zweideutige Formulierungen unschlüssig zwischen Schopenhauers negativ-metaphysischer Begründung der Moral und einer Rückkehr zum Glauben der Väter."96 Im Speziellen bezieht Habermas sich auf die Auffassung, „ohne ontologische Verankerung [sei] Wahrheit keine Idee mehr, sondern Waffe im Lebenskampf“, um seine alternative Position zu erläutern: „Gegenüber dieser eigenartig traditionellen Auffassung“

91 Habermas (2019), Bd. 1, 72.

92 Ebd., 191.

93 Ebd., Fn. 20.

94 Ders. (1991), 110-126.

95 Ebd., 111.

96 Ebd., 117. 
suche er „einen Begriff kommunikativer Vernunft zur Geltung [zu] bringen, der es gestattet, den Sinn des Unbedingten ohne Metaphysik zu retten. “97 Zur Verdeutlichung dieser Alternative wählt er die Formulierung „Transzendenz von innen“, wobei er festhält: „Nachmetaphysisches Denken unterscheidet sich von der Religion dadurch, dass es den Sinn des Unbedingten rettet ohne Rekurs auf Gott oder ein Absolutes. “98 In einem eigens dieser Konzeption gewidmeten Text ${ }^{99}$ schreibt Habermas, „dass wir im kommunikativen Handeln nicht umhin können, die Idee einer unversehrten Intersubjektivität vorauszusetzen; diese wiederum lässt sich als eine formale Kennzeichnung notwendiger Bedingungen für nichtantizipierbare Gestalten eines nicht-verfehlten Lebens begreifen“100. Näher erläutert er: „Die sprachliche Intersubjektivität überschreitet die Subjekte“; sie „kann deshalb ohne Preisgabe einer Transzendenz von innen des Begriffs eines Absoluten entraten. Auf dieses Erbe des hellenisierten Christentums können wir [...] verzichten“101. Habermas’ - nicht allein gegen Horkheimer gerichtetes Fazit lautet demgemäß: „Die Frage nach dem Sinn des Lebens ist nicht sinnlos. Dennoch reicht der Umstand, dass vorletzte Argumente weniger als Zuversicht einflössen, für die Begründung einer nur in religiöser Sprache zu belebenden Hoffnung nicht aus." ${ }^{102}$

Wie es scheint, werden diese Einsprüche dem Denken Horkheimers in wesentlichen Punkten nicht gerecht. Horkheimer spricht nicht als ein Individuum, das zu einer (vielleicht halbherzigen) „Rückkehr zum Glauben der Väter“ tendiert, sondern als ein Philosoph, der den Ort der Religion in jedem Menschen aufzuzeigen sucht. Sein Begriff der Religion erscheint nicht als „zweideutig“, sofern man in Erwägung zieht, dass Horkheimer sich an der kantischen Unterscheidung zwischen der in jedem „denkenden Menschen“ angelegten „Hoffnung“ und dem - jeweils für den eingeschränkten Kreis einer Gemeinschaft verbindlichen „historischen Kirchenglauben“ orientiert. Dem entspricht, dass Horkheimer die „Sehnsucht nach dem ganz Anderen“, die er selbst Atheisten zuschreibt, nirgendwo aus traditionellen Glaubenslehren abzuleiten vorschlägt, so dass sie sich als ein „abgemagertes“ Relikt der „weltanschaulichen Substanz des Glaubens“ darstellen würde. Habermas könnte sich in seiner Einschätzung Horkheimers an Hegels Auffassung orientiert haben, der zufolge die Aufklärung das Reich des

97 Ebd., 119.

98 Ebd., 125.

99 Ders., Exkurs: Transzendenz von innen, Transzendenz ins Diesseits, in: ders. (1991), 127-156.

100 Ders. (1991), 145.

101 Ebd., 156.

102 Ebd., 144. 
Glaubens „ausgeplündert“ und nur eine „Leere“ zurückgelassen hat, wodurch der Geist sich in folgender Lage vorfindet: „[I]ndem er über das Endliche, das der einzige Inhalt ist, hinausgehend nur das Leere findet, ist er ein reines Sehnen,

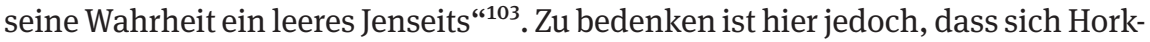
heimers Ausführungen zur „Sehnsucht nach dem ganz Anderen“ gerade nicht dem von Hegel kritisierten Phänomen der Aufklärung zuordnen lassen, sondern im Gegenteil ihrerseits dem Reduktionismus eines „,rein in der sinnlichen Wirklichkeit lebenden Bewusstseins“"104 entgegentreten. Gegenüber dem von einem empiristischen Kurzschluss geprägten Mainstream macht Horkheimer einen unverkürzten Begriff des Menschen geltend, der den Sinnanspruch, der unsere Praxis trägt, einschließt. So lässt sich eine Passage aus Horkheimers Notizen, die Habermas zitiert ${ }^{105}$, zugleich als eine Antwort auf Habermas lesen: „[Die Gesellschaftstheorie] hat die Theologie abgelöst, aber keinen neuen Himmel gefunden, auf den sie weisen kann, nicht einmal einen irdischen Himmel. Aus dem Sinn schlagen kann sie ihn freilich nicht, und darum wird sie immer wieder nach dem Weg gefragt, der dahin führt. Als ob es nicht gerade ihre Entdeckung wäre, dass der Himmel, zu dem man den Weg weisen kann, keiner ist. “106 Horkheimer stimmt auch in diesem Punkt mit Adorno überein, der geltend macht: „Die Frage nach dem Sinn des Lebens kann nicht ruhig gestellt werden in einem kollektiven, amelioristischen Handlungsbegriff“, und der weiß, „dass der Begriff des Sinns unaufgebbar ,Objektivität jenseits allen Machens` impliziert.“107

Als maßgebend für die Differenz zwischen Horkheimers Position und Habermas' nachmetaphysischem Denken erweist sich die unterschiedliche Auffassung von Kants Konzeption der „Postulate“. Habermas formuliert seine Lesart auf folgende Weise: „Schon Kant hat die Frage: Was dürfen wir hoffen? mit einem Postulat der praktischen Vernunft beantwortet, nicht mit einer vormodernen Gewissheit, die uns Zuversicht einflößen könnte. " ${ }^{108}$ Hier fällt zunächst eine Veränderung in der Ausgangsfrage auf: Während Kant mit der Frage „Was darf ich hoffen?“ indiziert, dass er von der Perspektive der ersten Person Singular ausgeht, lässt das von Habermas stattdessen eingesetzte „Wir“ bereits eine sozialtheoretische Zugangsweise erkennen. Signifikant ist ferner, dass Habermas’ Darstellung so klingt, als sei Kants Konzeption der Postulate als eine Theorie gedacht, die den

103 Hegel (1986), 423.

104 Ebd., 432.

105 Habermas (1991), 113.

106 Horkheimer (1974), 61.

107 Nagl (2010), 29; vgl. Adorno (1970), 367.

108 Habermas (1991), 145. 
aufgrund ihrer Endlichkeitserfahrungen verzweifelnden Menschen als ein philosophisches Trostwort angeboten werden könne. Damit gerät jedoch außer Sicht, dass für Kant der genuine Ort der Postulate die praktische Vernunft jedes Einzelnen ist, auch wenn die Menschen dies nicht explizit reflektieren ${ }^{109}$; nur aufgrund der Verankerung in dem je eigenen Vernunft-Bedürfnis können die Ideen von Gott und einem künftigen Leben Überzeugungskraft gewinnen. Wie sich gezeigt hat, greift Horkheimer genau diesen Gedanken auf, wenn er der Philosophie sowie den von dogmatischen Verkrustungen befreiten traditionellen Glaubenslehren die Aufgabe zuweist, die auf die Erfahrung der Endlichkeit bezogene Hoffnungsdimension wach zu halten bzw. deutlich zu machen. ${ }^{110}$

Dieses Anliegen Horkheimers wird verfehlt in einer Lektüre, die davon ausgeht, für die Philosophie der Gegenwart verbleibe nur eine Alternative: Nach der Zurückweisung aller Ansprüche auf einen logischen bzw. theoretischen Gottesbeweis sei das Thema Religion gänzlich $\mathrm{zu}$ verabschieden respektive in ein vormodernes Denken zu verweisen. Diese Auffassung lässt sich nicht darauf ein, dass Kant eine dritte Option der vernünftigen Argumentation - zwischen theoretischen Beweisen und einer radikalen Abkehr von der Religion - darlegt, indem er die „moralische Gewissheit“ aufzeigt. Da Horkheimer sich an dieser dritten Option orientiert, erscheint die Diagnose der „Zwiespältigkeit“ kaum als plausibel. Diese Diagnose ließe sich eher auf das nachmetaphysische Denken beziehen, wenn man sich vergegenwärtigt, dass in der Erläuterung des Anspruchs,

109 Wie Schnädelbach unterstreicht, ist zu beachten, dass es die „Perspektiven der 1. und der 3. Person analytisch zu unterscheiden“ gilt, „wenn man auf Horkheimer als Philosophen der Moral zu sprechen kommen möchte“ (Schnädelbach 1986, 56). Allerdings geht er der Perspektive der 1. Person nicht so weit nach, dass der Zusammenhang zwischen Moraltheorie und Philosophie der Religion (bei Horkheimer wie bei Kant) in Sicht käme.

110 In seinem aus Anlass des 90. Geburtstags von Horkheimer verfassten Artikel schreibt Habermas unter dem Zwischentitel „Theologie im Spätwerk?“: „Horkheimer wollte seinem ursprünglichen Impuls treu bleiben, ,im schlechten Bestehenden des Anderen eingedenk zu bleiben', ohne zur göttlichen Weisheit Zuflucht zu nehmen“ (Habermas 1985, 59). Dass Horkheimers Denken auf diese Weise ausdrücklich unter „das nachmetaphysische Denken“ subsumiert wird (ebd.), gibt freilich Anlass zur Frage, ob das eigentliche Anliegen der Konzeption der „Sehnsucht nach dem ganz Anderen“ adäquat erfasst ist. Zu bedenken ist jedenfalls, dass Horkheimer in seinem späten Gespräch über Paul Tillich bemerkte: „Ich glaube, es gibt keine Philosophie, zu der ich ja sagen könnte, die nicht auch ein theologisches Moment in sich trägt, denn es geht ja darum zu erkennen, inwiefern die Welt, in der wir leben, als ein Relatives zu interpretieren ist. Das wußten Kant und Schopenhauer, und ich meine, philosophische Bemühungen, die sich dessen nicht bewußt sind, sind keine“; Horkheimer, Werk und Wirken Paul Tillichs. Ein Gedenkbuch, Stuttgart o. J., 16, hier zit. aus Gumnior/Ringguth (1973), 131. Vgl. auch Horkheimer, Letzte Spur von Theologie Paul Tillichs Vermächtnis, in: ders. (1988), Bd. 7, 269-275. 
den es erhebt, eine immanente Spannung auftritt. Während Habermas zum einen geltend macht, „nachmetaphysisches Denken unterscheidet sich von der Religion dadurch, dass es den Sinn des Unbedingten rettet ohne Rekurs auf Gott oder ein Absolutes“111, räumt er zum anderen ein, dass die Konzeption der „Transzendenz von innen“ die letzten Sinnfragen dennoch offen lässt. ${ }^{112}$

Für die heutige Debatte zu dieser Thematik liegt die Bedeutung Horkheimers zweifellos darin, dass er die Frage nach dem Sinn nachdrücklich offen hält - auch mit der lapidaren Feststellung „die Tatsache bleibt, dass der Mensch sterben muss“ - und darauf insistiert, sie mit philosophischen Mitteln zu thematisieren. Was die „Behutsamkeit“ der Herangehensweise betrifft, für die er dabei plädiert, ist die Übereinstimmung mit Adornos Erkundung der Postulatenlehre im Auge zu behalten, deren Leitgedanke sich so transkribieren lässt: „Das, was in der metaphysischen Rede vom Absoluten vormals verhandelt wurde, gilt es - angesichts der durch die Monstrositäten des zwanzigsten Jahrhunderts verschärften Krise aller Theodizeen - nicht einfach ruhigzustellen, sondern in offenen Denkbewegungen, nachdenkend zu umkreisen."113 Freilich dürfte diese Art von Zurückhaltung der Diagnose Vorschub geleistet haben, bei Horkheimer zeige sich ein „zwiespältiges Verhältnis zur Religion“. Näher zu erkunden wäre daher, wie weit eine explizitere Rezeption der „dritten Option“, welche durch Kants Darlegung der Postulate der moralisch-praktischen Vernunft eröffnet wird, einer konsistenten Durchleuchtung der Thesen Horkheimers dienlich sein könnte. Der intendierten „Behutsamkeit“ würde dies nicht entgegenwirken, zumal auch Kant, wie oben erläutert, eine agnostische Haltung in seine Ausführungen einbezieht.

Im Blick auf die heutige Debatte ist ferner hervorzuheben, dass Horkheimers Weigerung, das Thema des Absoluten gänzlich in die theologische Vergangenheit zu verbannen, auch darin begründet ist, dass er die Wichtigkeit der moralischen Herzensbildung hervorzuheben sucht. Der von Habermas formulierten These, wonach ,,in der säkularisierten Welt die religiös instruierte Gewissensregung der Reue nicht mehr als vernünftig gilt"114, würde Horkheimer wohl - als einem empirischen Befund - zustimmen, jedoch mit dem Gestus seines Bedauerns, dass die „Gewissensbildung heute gefährdet ist“ (79). Wie Kant scheint er die gewissenhafte Auseinandersetzung mit dem je eigenen Versagen ${ }^{115}$ als ein

111 Habermas (1991), 125.

112 Ebd., 144.

113 Nagl (2010), 12.

114 Habermas (1991), 112.

115 Wie Kant erläutert, ist das Gewissen in unserer moralisch-praktischen Vernunft angelegt, nicht in einem göttlichen Gesetzgeber. Das Gewissen ist „das Bewusstsein eines inneren Gerichtshofes im Menschen“; somit ist es die Stimme des „inneren Richters“, die uns mit unseren 
Element des Bewusstseins der Kontingenz zu betrachten, „über dem die Sehnsucht steht, dieses irdische Dasein möge nicht absolut, nicht das letzte sein“ (67). Im Allgemeinen ist aufschlussreich, dass Horkheimer bereits 1962 nachdrücklich auf die Relevanz Kants für die Auseinandersetzung mit gegenwärtig dominierenden Reduktionismen hingewiesen hatte. In seinem Vortrag „Kants Philosophie und die Aufklärung“ hatte er betont, „dass die Rezeption der Kantschen Aufklärung [...] an der Zeit ist. Wenn in den gesellschaftlichen Formen, die in den kommenden Jahrzehnten auf der Welt sich ausbreiten werden, die theoretischen wie praktischen Ideen, wie sie von Kant entfaltet wurden, nicht überleben, wenn sie dem, was droht, sich nicht entgegensetzen, wird der Rückfall unaufhaltsam sein.“116

\section{Literatur}

Adorno, T. W. (1970), Negative Dialektik, Frankfurt am Main.

Brandt, R. (2010), Immanuel Kant - Was bleibt?, Hamburg.

Byrne, Peter (2007), Kant on God, Aldershot u. Burlington, Vt.

Dietrich, K. (2009), Die religiöse Wende des alten Philosophen, URL: https://www. deutschlandfunkkultur.de/die-religioese-wende-des-alten-philosophen.950. de.html?dram:article_id=137899 (12.11.2020).

Eitler, P. (2009), Gott ist tot - Gott ist rot. Max Horkheimer und die Politisierung der Religion um 1968, Frankfurt am Main.

Gumnior, H. (1970), Vorwort des Herausgebers, in: Horkheimer (1970), 5-6.

Gumnior, H., u. Ringguth, R. (1973), Max Horkheimer in Selbstzeugnissen und Bilddokumenten, Reinbek.

Habermas, J. (1985), Die revolutionäre Hoffnung ist ortlos geworden. Das nachmetaphysische

Denken des skeptischen Moralisten Horkheimer, in: Die Zeit, 27.9.1985, 59.

Habermas, J. (1991), Texte und Kontexte, Frankfurt am Main.

Habermas, J. (2019), Auch eine Geschichte der Philosophie, 2 Bde., Berlin.

Hegel, G. W. F. (1986), Phänomenologie des Geistes (= Werke 3), Frankfurt am Main.

Horkheimer, M. (1922), Zur Antinomie der teleologischen Urteilskraft (Diss.), Frankfurt am Main. Horkheimer, M. (1925), Kants Kritik der Urteilskraft als Bindeglied zwischen theoretischer und praktischer Vernunft (Habil.), Frankfurt am Main.

Horkheimer, M. (1968), Kritische Theorie. Eine Dokumentation, hg. v. Schmidt, A., 2 Bde., Frankfurt am Main.

Verfehlungen - und so mit unserer Endlichkeit -konfrontiert (Kant 1963g, 573). Kant beobachtet freilich auch, dass die Stimme des Gewissens weitgehend unterdrückt werden kann - durch einen „Hang, sich an dessen Urteil nicht zu kehren“ -, und hält deshalb fest, dass es zu den Pflichten eines jeden gehört, „sein Gewissen zu kultivieren“ (ebd., 532).

116 Horkheimer, Um die Freiheit, Frankfurt am Main 1962; hier zit. nach dems. (1974a), 214. 
Horkheimer, M. (1970), Die Sehnsucht nach dem ganz Anderen. Ein Interview mit Kommentar von Helmut Gumnior, Hamburg.

Horkheimer, M. (1974a), Zur Kritik der instrumentellen Vernunft, Frankfurt am Main.

Horkheimer, M. (1974b), Notizen 1950 bis 1969 und Dämmerung, Notizen in Deutschland, hrsg. v. Brede, W., u. Schmidt, A., Frankfurt am Main.

Horkheimer, M. (1988), Gesammelte Schriften, hg. v. Schmidt, A., u. Schmid Noerr, G., 19 Bde., Frankfurt am Main.

Kant, I. (1900 ff.), Kants gesammelte Schriften, hg. v. d. Königl. Preuß. Akad. d. Wiss., Berlin [AA].

Kant, I., (1963a), Beantwortung der Frage: Was ist Aufklärung?, in: ders. (1963j), Bd. 6, 51-61 [WA].

Kant, I., (1963b), Das Ende aller Dinge, in: ders. (1963j), Bd. 6, 173-190 [ED].

Kant, I., (1963c), Idee zu einer allgemeinen Geschichte in weltbürgerlicher Absicht, in: ders. (1963j), Bd. 6, 31-61.

Kant, I. (1963d), Kritik der praktischen Vernunft, in: ders. (1963j), Bd. 4, 103-302 [PV].

Kant, I., (1963e), Kritik der reinen Vernunft, in: ders. (1963j), Bd. 2 [RV].

Kant, I. (1963f), Kritik der Urteilskraft, in: ders. (1963j), Bd. 5, 173-620 [KU].

Kant, I., (1963g), Die Metaphysik der Sitten, in: ders. (1963j), Bd. 4, 309-634.

Kant, I. (1963h), Die Religion innerhalb der Grenzen der bloßen Vernunft, in: ders. (1963j), Bd. 4, 649-879 [RG].

Kant, I. (1963i), Was heißt: sich im Denken orientieren?, in: ders. (1963j), Bd. 3, 267-283 [DO].

Kant, I. (1963j), Werke in sechs Bänden, hg. v. Weischedel, W., Darmstadt.

Kant, I. (2004), Vorlesung zur Moralphilosophie, hg. v. Stark, W., Berlin.

Langthaler, R. (2018), Kant über den Glauben und die „Selbsterhaltung der Vernunft“, München.

Lutz-Bachmann, M. (1986), Humanität und Religion. Zu Max Horkheimers Deutung des Christentums, in: Schmidt, A., u. Altwicker, N. (Hg.), Max Horkheimer heute: Werk und Wirkung, Frankfurt am Main, 108-128.

Nagl, L. (2010), Das verhüllte Absolute. Essays zur zeitgenössischen Religionsphilosophie, Frankfurt am Main.

Nagl-Docekal, H. (2010), Ist die Konzeption des „Herzenskündigers“ obsolet geworden?, in: Buchheim, T., et al. (Hg.), Philosophisches Jahrbuch im Auftrag der Görres-Gesellschaft, 2. Halbbd., 319-338.

Nagl-Docekal, H. (2014), Innere Freiheit. Grenzen der nachmetaphysischen Moralkonzeptionen, Berlin.

Nagl-Docekal, H. (2020, i. E.), Kant's Concept of Reasonable Hope, in: Lichner, M. (Hg.), Proceedings of the International ESCT Congress „Where Does our Hope Lie?“, Berlin u. a.

O’Neill, O. (2003), Vernünftige Hoffnung. Tanner Lecture 1 über Kants Religionsphilosophie, in: Nagl, L. (Hg.), Religion nach der Religionskritik, Wien u. München, 86-110.

Reijen, W. v. (1982), Horkheimer. SOAK-Einführungen 10, Hannover.

Rosen, Z. (1995), Max Horkheimer, Beck'sche Reihe Denker, München.

Schmidt, A. (1986), Die ursprüngliche Konzeption der Kritischen Theorie im frühen und mittleren Werk Max Horkheimers, in: Honneth, A., u. Wellmer, A. (Hg.), Die Frankfurter Schule und die Folgen, Berlin, 89-112.

Schmidt, A., u. Altwicker, N. (Hg.) (1986), Max Horkheimer heute: Werk und Wirkung, Frankfurt am Main. 
Schnädelbach, H. (1986), Max Horkheimer und die Moralphilosophie des deutschen Idealismus, in: Schmidt/Altwicker (1986), 52-78.

Der Spiegel (1970), Was wir ,Sinn“ nennen, wird verschwinden. Spiegel-Gespräch mit Max Horkheimer, in: Der Spiegel, 5.1.1970, 79-84.

Stangneth, B. (2003), Anmerkungen des Herausgebers, in: Kant, I., Die Religion innerhalb der Grenzen der bloßen Vernunft, Hamburg, 275-308.

Wenzel, U. J. (1995), Sehnsucht nach dem ganz Anderen. Über Max Horkheimer - aus Anlaß seines 100. Geburtstags, in: Neue Zürcher Zeitung, 10.2.1995, 37-38.

Wood, A. W. (1992), Rational theology, moral faith, and religion, in: Guyer, P. (Hg.), The Cambridge Companion to Kant, Cambridge, 394-416. 